stants of the Smithsonian double-tube, water-flow stcndard pyroheliometer and of the sub-standard silver disk pyroheliometer S.I.5 has been confirmed. The researches of the Division of Radiation and Organisms continue to be concerned chiefly with the physiological and biochemical processes by which light regulates the growth of plants and the mechanisms of the action of the auxin type of growth hormone. Investigations of the effect of plant-growth regulators on the salt exchange of plants indicated that high salt - low carbohydrate plants lose salt more rapidly when treated with ammonium $2: 4$-dichlorophenoxyacetate, while low salt-high carbohydrate plants absorb salt less rapidly compared with untreated plants.

Of the seven hundred visitors to the Canal Zone Biological Area, fifty-seven were scientific workers who used the facilities of the station, considerably improved during the year, chiefly for biological and photographic studies. The $1,021,938$ packages of government scientific and literary publications handled by the International Exchange Service during the year, an increase of 20,324 packages, included consignments to all countries except China, North Korea and Rumania. A grant of 6,000 dollars towards rising transport costs was received from the National Science Foundation. The Service now dispatches abroad sixty-three full and forty-two partial sets of United States official publications in exchange for the official publications of other Governments.

\section{WOOL INDUSTRIES RESEARCH ASSOCIATION}

\section{REPORT FOR THE YEAR 1953-54}

T

HE report of the Director of Research of the Wool Industries Research Association for 1953 $54^{*}$ expresses the view that the statutory levy for research, which has now been in operation for two years, has both increased the interest of members and also enabled the Wool Textile Research Council to clarify the relation of research at the universities and technical colleges to that of the Association. The pilot-scale scouring plant was completed towards the end of the year and has given results well up to commercial standard. Data have been obtained on the possibility of alkali damage to wool during commercial scouring. A prototype of the automatic controller for the woollen card designed in the Association's laboratories some years ago is undergoing trials in a mill and seems to be suitable for commercial use ; and a second controller, which may be particularly suitable for cards with ball and bank feeds, is also under trial. Commercial development of the Raper drawing system, incorporating autolevellers, has now been taken up, and a most encouraging number of firm orders has been placed by British spinners ; a great deal of the early work on this new system was done in the Association's laboratories. Much new information about the drafting process has been obtained by the use of radioactive tracers, and considerable progress has also been made in an attempt to understand theoretically how tensions are generated in yarns being drawn from packages, and

* Wool Industries Research Association. Publication No. 199: Report of the Director of Research for 1953-54. Pp. 32. (Leeds Wool Industries Research Association, 1954.) how this tension should vary with the dimensions of the package and the position of the twizzle through which the yarn must pass.

In chemical technology 449 investigations were carried out on behalf of member firms. Scouring experiments continued, and a large-scale trial demonstrated that bulk removal of cellulose acetate fibre from rags is technically feasible. The practicability of dyeing wool at high temperatures without undue damage to fibres has been confirmed, provided the $p H$ of the dye liquor and the time of treatment are kept within limits. Experience has shown that the Association's fineness meter, based on the air-flow method, is quick and reliable and that the accuracy in the mean fibre diameter of tops is at least as high as that obtained with a projection microscope. A rapid method of comparing the strength of two yarns has been devised, which can be used where no strength machine is available. Work in the Biology Department on Scots blackface, Herdwick and Suffolk breeds of sheep has emphasized the importance of the secondary to primary follicle ratio in the development of fine wools, and the effect of breeding and of nutrition on this ratio is being studied.

The use of starch columns together with fraction cutters for quantitative estimation of amino-acids by colorimetric and radioactive methods continued, and by the method of hydrazinolysis the carboxy terminal end-groups of wool have been found to be serine, glycerine, threonine and alanine. A study of the effect of dry chlorination on dyed nylon has been completed. Experiments with textiles and ionexchange resins have shown the electrolytic nature of charge separation by contact between dissimilar polar polymers, the sign of the charge being determined by the excess of freely diffusible ions in the polymer. Complete X-ray data have been obtained for the hydrochloride and hydrobromide of glycyl-t-alanine, and a Fourier projection has been determined which gives an accurate picture of the atomic arrangement.

\section{ROYAL SOCIETY DEPOSITORY OF UNPUBLISHED MATHEMATICAL TABLES}

$\mathrm{T}$ HE following is a list of accessions to the Royal Society's depository of unpublished mathematical tables since the publication of the last list in Nature $(171,1140 ; 1953)$ :

(22) Factorisation des nombres $2 N^{4}+1, N \leqslant 1000$ (A. Gloden) ;

(23) Factorization of $N=3 n^{4}-1,0<N \leqslant 1000$ (A. Ferrier) ;

(24) High-accuracy square- and cube-roots (D. F. Ferguson, C. E. Gwyther and J. C. P. Miller);

(25) A solution of the equation $\left(y^{\prime \prime}\right)^{2}=y y^{\prime}$;

(26) Table of

$F(\beta, \rho)=\frac{2}{\sqrt{ } \pi} \frac{\exp \left(-\rho^{2}\right)}{\beta^{2}} \int_{0}^{\beta} I_{0}(2 \rho \eta) \exp \left(-\eta^{2}\right) \eta \mathrm{d} \eta$;

(27) Tables of $F(x)=2 x x_{n=0}^{\infty}\left\{x^{2}+(2 n+1)^{2}\right\}^{-3 / 2}$ and of $x^{-1} F^{3}(x)$;

(28) Table of $G(x)=6 x^{2} \sum_{n=0}^{\infty}\left\{x^{2}+(2 n+1)^{2}\right\}^{-5 / 2}$; 